\title{
New developments in ambient noise analysis to characterise the seismic response of landslide-prone slopes
}

\author{
V. Del Gaudio ${ }^{1}$, J. Wasowski ${ }^{2}$, and S. Muscillo ${ }^{3}$ \\ ${ }^{1}$ Dipartimento di Scienze della Terra e Geoambientali, Università degli Studi di Bari “Aldo Moro”, via E. Orabona, \\ 4 - 70125 Bari, Italy \\ ${ }^{2}$ Consiglio Nazionale delle Ricerche - Istituto di Ricerca per la Protezione Idrogeologica, via Amendola, 122 I, \\ 70126 Bari, Italy \\ ${ }^{3}$ Dipartimento di Scienze della Terra e Geoambientali, Università degli Studi di Bari “Aldo Moro”, via E. Orabona, \\ 4 - 70125 Bari, Italy
}

Correspondence to: S. Muscillo (sandro.muscillo@uniba.it)

Received: 15 January 2013 - Published in Nat. Hazards Earth Syst. Sci. Discuss.: 17 April 2013

Revised: 4 July 2013 - Accepted: 8 July 2013 - Published: 20 August 2013

\begin{abstract}
We report on new developments in the application of ambient noise analysis applied to investigate the dynamic response of landslide-prone slopes to seismic shaking, with special attention to the directional resonance phenomena recognised in previous studies. These phenomena can be relevant for seismic slope susceptibility, especially when maximum resonance orientation is close to potential sliding directions. Therefore, the implementation of an effective technique for site response directivity detection is of general interest. In this regard methods based on the calculation of horizontal-to-vertical noise spectral ratio (HVNR) are promising. The applicability of such methods is investigated in the area of Caramanico Terme (central Italy), where ongoing accelerometer monitoring of slopes with different characteristics offers the possibility of validation of HVNR analysis. The noise measurements, carried out in different times to test the result repeatability, revealed that sites affected by response directivity persistently show major peaks with a common orientation, consistent with the resonance direction inferred from accelerometer data. In some cases such a directivity turned out parallel to maximum slope direction, but this cannot be considered a systematic feature of slope dynamic response. At sites where directivity is absent, the HVNR peaks do not generally show a preferential orientation, with rare exceptions that could be linked to the presence of temporarily active sources of polarised noise. The observed variations of spectral ratio amplitude can be related to temporal changes in site conditions (e.g. groundwater level/soil water
\end{abstract}

content variations affecting $P$ wave velocity and Poisson's ratio of surficial layer), which can hinder the recognition of main resonance frequencies. Therefore, we recommend conducting simultaneous measurements at nearby sites within the same study area and repeating measurements at different times in order to distinguish significant systematic polarisation caused by site-specific response directivity from polarisation controlled by properties of noise sources. Furthermore, an analysis of persistence in noise recordings of signals with systematic directivity showed that only a portion of recordings contains wave trains having a clear polarisation representative of site directional resonance. Thus a careful selection of signals for HVNR analysis is needed for a correct characterisation of site directional properties.

\section{Introduction}

Several studies have reported evidence that landslide triggering during earthquakes can be considerably influenced by ground motion amplification related to topography (e.g. Harp et al., 1981; Harp and Jibson 2002; Sepúlveda et al., 2005; Meunier et al., 2008) and/or subsoil physical characteristics (especially impedance contrast between surface material and substratum: cf. Bourdeau and Havenith, 2008; Bozzano et al., 2008). However, the dynamic response of marginally stable slopes under seismic shaking is still difficult to understand and predict: indeed, it is characterised by a complex 
interaction of different factors (topography, slope material properties, 3-D shape of geological bodies, discontinuity systems) concurring to produce effects of directional resonance. Such effects have been revealed by instrumental recordings of seismic ground motion at landslide-prone areas (Del Gaudio and Wasowski, 2007, 2011; Gallipoli and Mucciarelli, 2007; Garambois et al., 2010; Moore et al., 2011).

The presence of a strong anisotropy in site response can have important implications for the susceptibility of slopes to seismic failures, enhancing it where directions of potential sliding and of maximum amplification are similar. However, a clear comprehension of factors controlling the occurrence of site response directivity is still lacking; thus, the characterisation of dynamic response of slopes needs to be supported by ground motion data acquisition. The direct assessment of site response properties requires the comparison between several seismic event recordings at study sites and at nearby reference sites not affected by resonance phenomena (Borcherdt, 1970), according to the so-called SSR technique (standard spectral ratio). However, regional-scale longterm accelerometer monitoring of landslide-prone slopes appears impractical. Instead, the development of site response characterisation based on the analysis of short-term recordings of ambient seismic noise with portable instruments represents a promising alternative approach. This approach is based on Nakamura's method (Nogoshi and Igarashi, 1971; Nakamura, 1989), also known by the acronym HVNR (horizontal-to-vertical noise ratio), consisting of analysing the spectral ratios between horizontal and vertical components of ambient noise recordings, searching significant peaks of $H / V$ spectral ratios, which are interpreted as indicative of site resonance properties. The underlying postulate is that ambient noise consists mainly of surface waves (Rayleigh and Love) and/or body shear waves reflected and refracted inside shallow layers characterised by a strong impedance contrast. The presence of $H / V$ peaks at site resonance frequencies is explained by assuming that horizontal and vertical components of noise wave field have a comparable amplitude at the substratum (within an approximation factor of 2) and that only horizontal components are significantly amplified by the effect of shallow layers. Some preliminary tests on landslide areas showed that an analysis of azimuthal variation of $H / V$ spectral ratios can reveal the occurrence and orientation of directional resonance possibly related to sliding directions (Del Gaudio et al., 2008).

Despite its uncertain theoretical bases (cf. BonnefoyClaudet et al., 2006), the HVNR method proved to be an effective technique in investigating resonance frequencies under simple site conditions characterised by soft surface layers overlying a more rigid substratum (Lermo and ChávezGarcía, 1994). Indeed, regardless of the nature of the noise wave field, the $H / V$ peaks are observed at the resonance frequency of the $S$ waves even when the noise is dominated by Rayleigh waves (Asten, 2004). However there are difficulties in inferring amplification factors from HVNR, because the amplitude of the $H / V$ spectral ratios, even though correlated to amplification factor, may not be representative of its actual value and can change according to the nature of the noise wave field (Albarello and Lunedei, 2009).

The assessment of amplification is even more difficult in geologically and geomorphologically complex site conditions like those of landslide areas, where directivity represents an important aspect of site response. The standard HVNR measurements make use of a geometric mean of the two horizontal spectra to calculate $H / V$ ratios, then averaging the ratios obtained from a large number of recording time windows. This is justified, in the case of 1-D layering conditions, by the assumption of an isotropic site response. In this way the effects of differently polarised surface wave trains and of body $S$ waves propagating with different incidence angles are averaged, correcting the bias that would result from the analysis of waves coming from a single sources of polarised noise. The averaging over multiple time windows allows also estimating standard deviation of spectral ratios, which helps to distinguish whether the $H / V$ values are representative of persistent spectral properties of site response, or are affected by a strong variability related to properties of transient noise sources (Castellaro and Mulargia, 2009).

When site response cannot be considered isotropic, as in the case of landslide-prone slopes, the geometric averaging between horizontal components is not justified and one can focus on analysing directional variations of site responses. In this case, however, the calculation of azimuthal variation of HVNR values can be biased by the presence of persistent source of polarised noise. This problem can be exacerbated when site response analysis is extended to relatively low frequencies (i.e. longer wavelengths), which are of interest in the context of seismic triggering of large landslides. Noise spectrum frequencies below $1 \mathrm{~Hz}$ are dominated by a ubiquitous "microseismic" signal (Peterson, 1993), distinct from the anthropogenic "microtremors" observed at higher frequencies. The microseismic signal was recognised as an effect of sea wave energy coupling with solid earth vibrations, showing a major peak between 0.1 and $0.4 \mathrm{~Hz}$ (Haubrich et al., 1963), consisting of Rayleigh waves excited by sea water pressure perturbations on inshore ocean bottom (Tanimoto, 2007). An analysis of the location of microseismic sources showed that they undergo seasonal variations related to meteorology-dependent changes of ocean swells (Schimmel et al., 2011).

Microseismic signal can propagate over very long distances; thus one can expect that ambient noise analysis at microseismic frequencies will show signals with seasonally varying Rayleigh-type polarisation, originated by sources located thousands of kilometres away from the recording sites. Bromirski et al. (2005) pointed out a distinction between microseisms having peaks around $0.15 \mathrm{~Hz}$, which can travel with low attenuation over very long distances, and those having peaks at frequencies between 0.2 and $0.3 \mathrm{~Hz}$, which are much more attenuated and observed only in coastal areas 
relatively near the source. At frequencies larger than $0.3 \mathrm{~Hz}$ microseismic energy does not seem to propagate through the ocean floor beyond a few hundreds of $\mathrm{km}$, and signals observed at these frequencies are generally excited by windgenerated local waves.

Therefore, while analysing ambient noise of frequencies below $1 \mathrm{~Hz}$ to characterise local dynamic response of slopes to seismic shaking, problems can be encountered in distinguishing site-specific directivity properties of site response and polarisation due to the presence of persistent sources of polarised noise. Furthermore, considering the possible effect of oceanic sources of polarised noise, the analysis cannot be reliably extended below $0.3 \mathrm{~Hz}$, whereas frequencies between 0.3 and $1 \mathrm{~Hz}$ can be exploited taking into account the possibility of a bias related to microseismic signals coming from the nearest coastal areas. This problem can be faced by acquiring simultaneous recordings at different sites in the same study area, which helps to distinguish low-frequency polarisation specific to certain sites from that having a "regional" diffusion related to an external origin. Furthermore, the repetition of measurements at different times (possibly in different seasons) can reveal whether a polarisation shows a site-specific character or a seasonal variability.

In this paper we present new results of applications of the HVNR technique on slopes affected by or prone to failures, focusing on the uncertainties in data interpretation related to the space-time variation of noise wave field properties. After describing the study area characteristics and the data processing solutions adopted, we present and discuss the results from sites for which comparative seismic response data were provided by accelerometer recordings of recent earthquakes, as well as results from several other slope sites.

\section{Measurements}

Ambient noise measurements were carried out using two kinds of instruments, a tomograph (i.e. an instrument specifically devised to record small-amplitude ground vibrations) and a portable broad-band seismograph. We employed Tromino tomographs (model ENGY PLUS, http://www.tromino.eu), which are three-component, compact, "all-in-one" instruments including both sensors and data acquisition system, working at frequencies down to $0.3 \mathrm{~Hz}$.

When investigating low-frequency ambient noise, we also tested the use of a portable broad-band seismometer, Trillium Compact, combined with an acquisition unit, Taurus, (both produced by Nanometrics) providing an homogeneous instrumental response in the interval $0.02-50 \mathrm{~Hz}$.

Given the need to analyse noise up to periods of about $3 \mathrm{~s}$, data were acquired with sessions lasting at least a few tens of minutes, thus satisfying the SESAME project guideline recommendations of obtaining data sufficient to extract not less than 200 cycles of the longest period to be analysed (Bard and The SESAME Team, 2004). However, following the results of first tests, the duration of data acquisition sessions was considerably extended, taking into account that (i) in comparison to the standard applications, directional analysis necessitates a larger number of time windows to increase the probability of recording signal noise coming from different directions; (ii) a certain number of time windows has to be discarded from the analysis if the recordings are characterised by transient signal coming from temporary and very close sources of ground vibration, whose polarisation is more likely to reflect source directivity properties rather than sitespecific effects. Furthermore, building upon the previous experiences, the most recent measurements were conducted via simultaneous recordings at different nearby sites with two instruments, often recording continuously at a "reference" station for several hours and moving a "rover" recorder to different sites in the same study area.

\subsection{Study area setting}

Our first HVNR measurements on landslide-prone slopes were carried out in the area of Caramanico Terme, in Abruzzi region (central Italy). The study area is located in a valley whose flanks are characterised by Pliocene clay-rich formations mantled by thick Quaternary colluvial deposits (Fig. 1). The town of Caramanico Terme is overlooked by the Colle Alto hill, which constitutes a caprock made of Quaternary carbonate megabreccias. The caprock is bounded by very steep scarps which are frequently affected by rockfalls.

The instability of the Caramanico hillslopes is linked to the particular hydrogeological setting characterised by the presence of thick caprock (main groundwater aquifer in the area), middle-upper slope colluvial covers capable of hosting a shallow aquifer, and underlying low-conductivity mudstone substratum (Fig. 1). The available groundwater data, albeit limited, indicated highly variable water level rises (from less than a metre to $11 \mathrm{~m}$ ), registered in the Casagrande and open-pipe piezometers sited in the colluviums (Wasowski, 1998). This variability can be in part related to the seasonal precipitation patterns with water level maxima following the groundwater recharge during late-fall/winter/early-spring period. The lowest piezometric levels are typically encountered in early fall, following dry and hot summer period.

Topographic and geological conditions make the Caramanico area susceptible to seismic triggering of different types of landslides, as repeatedly occurred during past earthquakes (Wasowski and Del Gaudio, 2000). A local accelerometer network was installed there in 2002 to study slope dynamic response to seismic shaking under different lithological and topographic conditions (Del Gaudio and Wasowski, 2007, 2011). Data acquired by this network offer the possibility of validating site response information that can be derived from ambient noise analysis. Thus, first tests of HVNR measurements were carried out at sites of accelerometer stations (Fig. 1). One of these stations, CAR2, 

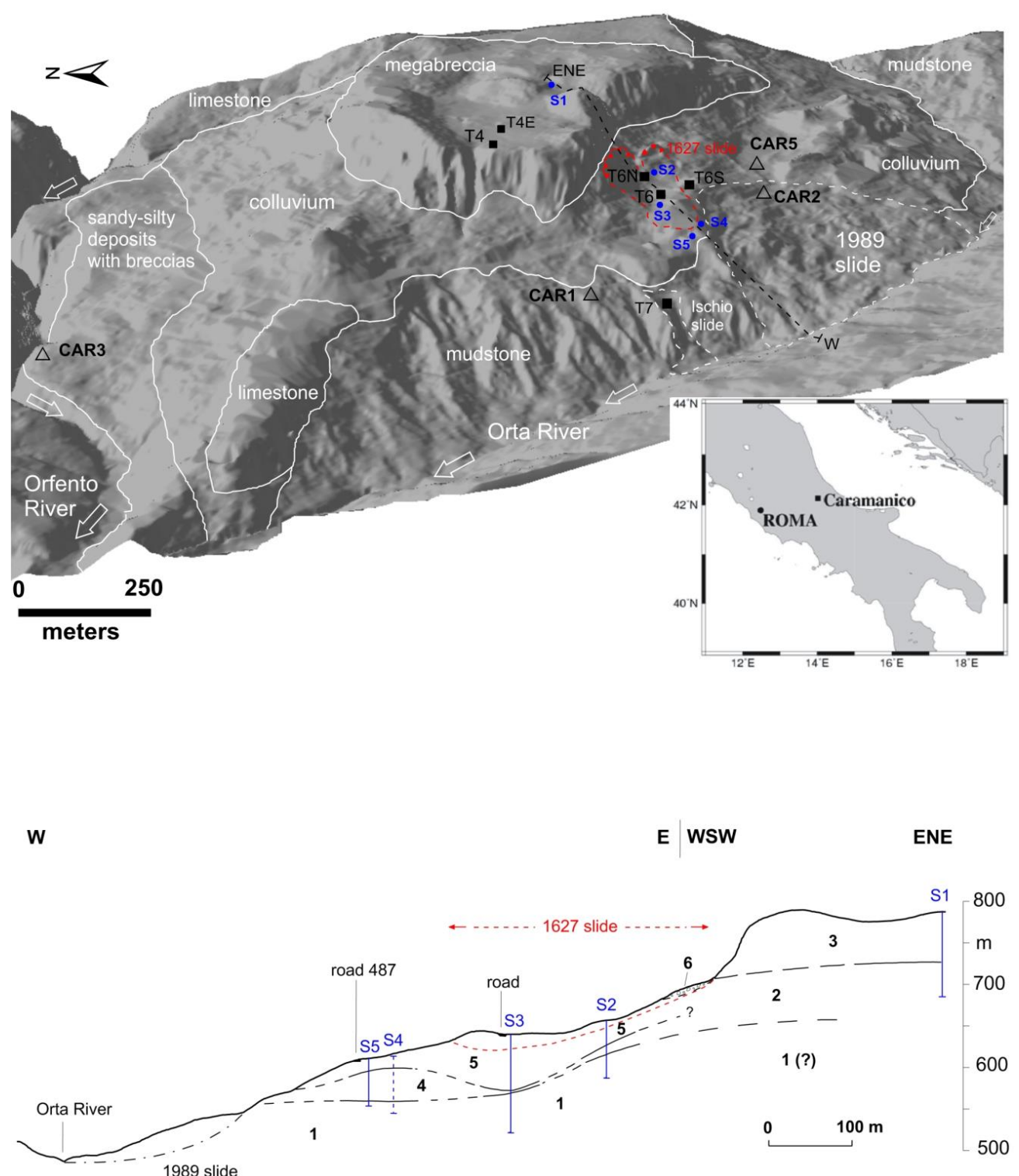

Fig. 1. Upper: geographic location of the Caramanico test area (inset) and DEM showing lithology and measurement sites (modified after Del Gaudio and Wasowski, 2011). White continuous and dashed lines mark, respectively, lithological contacts and boundaries of investigated landslides; two possible source areas for the 1627 landslide (in red) are indicated. CAR1-5 marks the location of the accelerometer stations (reference station CAR4, located $2.5 \mathrm{~km}$ SE of Caramanico, is not shown); T4, T4E, T6, T6N, T6S and T7 indicate the additional sites of HVNR measurements discussed in the paper; S1-5 shows borehole positions; dashed black line indicates location of geological profile. Lower: simplified geological profile of the slope affected by Colle Alto hillslope (modified after Wasowski and Del Gaudio, 2000). Symbols: S1-5 = boreholes; 1 = mudstone substratum; 2 = clay-rich silty sandy deposits found in borehole S1, including variable admixtures of carbonate debris; clasts are subrounded in the lower third part of the borehole; $3=$ carbonate megabreccia (caprock); $4=$ remoulded clayrich materials containing variable amounts of angular clasts, of inferred mass movement origin; $5=$ variably cemented carbonate breccias; $6=$ recent carbonate detritus of rockfall origin. Dashed red line indicates inferred subsurface limit of the 1627 landslide.

is positioned on the head of a landslide that in 1989 involved colluvial deposits about $40 \mathrm{~m}$ thick overlying mudstones. Two other stations are located on the same slope, but outside the limits of the 1989 landslide: one (CAR1) is located on an outcrop of the Pliocene mudstone constituting the substratum of the 1989 landslide, whereas another station
(CAR5) is located on the same kind of material affected by the 1989 failure, but about $200 \mathrm{~m}$ away, upslope of the landslide crown, on a stable, gently inclined area $\left(<7^{\circ}\right)$.

Two stations are sited on rock: one (CAR3) is located at the rim of a $50 \mathrm{~m}$-deep ESE-WNW-oriented gorge, on $10 \mathrm{~m}$ of carbonate breccias that overly Miocene limestones, 
whereas the other (CAR4) is located on an outcrop of the same limestones as at CAR3, but on a relatively flat surface (inclination $<7^{\circ}$ ) located at about $2.5 \mathrm{~km}$ distance from Caramanico Terme. CAR4 is used as a reference to compare site response of the other stations.

Additional ambient noise recordings were carried out on three other landslide-prone slopes in Caramanico (Fig. 1). One of these sites (T7) is on the Ischio landslide, a $250 \mathrm{~m}$ long, complex mass movement located on the lower slopes of the river valley. During its last major re-activations in 1973 and 1996-1997, retrogressive, multiple rotational movements in the uppermost part of the slide affected a fewtens-of-metres-thick carbonate breccia caprock overlying the Pliocene-age mudstone substratum (Wasowski, 1997). The actual depth of the basal slip surface in the mudstones is unknown. The presence of shallow translational movements was observed in the middle-lower part of the slide, where the thickness of carbonate debris is less than $5 \mathrm{~m}$.

Measurements were also conducted at three different points (T6, T6N, T6S) of the slope affected by a deep landslide, which involved few-tens-of-metres-thick carbonate debris overlying Pliocene mudstones. The failure was triggered in 1627 by a magnitude $6.7-7$ earthquake which occurred about $120 \mathrm{~km}$ from Caramanico. The long distance from the earthquake source suggested that site amplification was a factor in landslide triggering (Wasowski et al., 2013).

Finally, ambient noise measurements were also carried out at two sites on top of the megabreccia caprock, one (T4) on the rim of a steep scarp, and the other (T4E) a few tens of metres away from the scarp edge.

\section{Data processing}

Data acquired during recording sessions were subdivided into time windows of 30 s (i.e. 10 times the longest period of interest), applying a linear detrending to each window to remove long-term drift. Spectra were calculated for each component and smoothed using a triangular average on frequency intervals of $\pm 10 \%$ of the central frequency. Horizontal to vertical spectral ratios were then calculated for horizontal components along directions at $10^{\circ}$ azimuth intervals. Following the recommendation of Castellaro and Mulargia (2009), spectrograms reporting spectral ratios as a function of time for $\mathrm{E}-\mathrm{W}$ and $\mathrm{N}-\mathrm{S}$ components were examined to discard time windows having anomalously high spectral ratio values resulting from strong transient signals. Finally, the average spectral ratios $H / V$ of all the accepted time window intervals were calculated for each direction.

The difficulty in establishing whether observed peaks are significant persistent features attributable to site response, or reflect transient effects due to noise source characteristics, is commonly encountered when interpreting the HVNR values. Bard and The SESAME Team (2004) proposed that a minimum threshold of 2 for peak amplitude and a small standard deviation around the mean HVNR values obtained from all the analysed time windows can be used to assess the significance of $H / V$ peak. However, these criteria, defined for 1-D layering conditions, appear too restrictive for a directional analysis under complex site conditions that are typical of landslide areas. Indeed, when analysing azimuthal variation of $H / V$ ratios, one should keep in mind that a source of variability could result also from the recording of differently polarised wave trains arriving at different times from different noise sources around the measurement site. In such a case the effect of source-controlled polarisation would add to sitespecific directivity, increasing standard deviation around the mean HVNR values along each direction.

Therefore, carefully defined criteria are needed to infer site-specific directivity from HVNR data, through an identification of a systematic preferential orientation of $H / V$ relative maxima. Del Gaudio et al. (2008) considered the distribution of HVNR values as function of azimuth and frequency and proposed an approach based on the detection of multiple major peaks having coherent orientation (within $30^{\circ}$ ) and satisfying the following significance criteria:

1. amplitude of $H / V$ relative maximum larger than 2;

2. ratio between $H / V$ maximum and minimum found at the same frequency (typically along an approximately orthogonal direction) larger than 1.5 (which implies a shaking energy along maximum direction larger by more than a factor of 2 in comparison to minimum).

In order to facilitate identification of directivity, we propose here an additional step consisting in the evaluation of the temporal recurrence of signals having coherent polarisation. The procedure consists in finding, preliminarily, all the relative maxima appearing in the distribution of HVNR values and satisfying the criteria (a) and (b) mentioned above. This is done both for mean HVNR values and for HVNR relative to each time window taken separately. Comparing each peak of mean HVNR values with the peak that in each time window shows a minimum difference in frequency and azimuth from the mean $H / V$ peak, standard deviations can be estimated for peak frequency, azimuth and amplitude.

Then we examine the occurrence rate of significant directional $H / V$ peaks among the time windows of a recording session. Since the frequency of peaks is typically affected by an uncertainty (expressed through standard deviation) of about $0.25 \mathrm{~Hz}$, peaks that along each orientation (spaced by $10^{\circ}$ ) have frequencies falling within a $0.5 \mathrm{~Hz}$ interval are grouped together in separate bins. Then, for each frequency/azimuth bin the percentage of time windows showing significant $H / V$ peaks belonging to that bin is calculated. The results can be represented through a 3-D histogram, where the column height represents the occurrence rate, and a colour scale is used to represent the mean $H / V$ values of the peaks belonging to each bin. 
We define the resulting percentage as "directional $H / V$ peak occurrence rate" (DHVPOR). A concentration of high percentage values around a given frequency and azimuth implies that a large amount of the recording time windows shows persistently directional peaks with those frequency/azimuth characteristics.

The outcomes of a single recording session may not always be considered conclusive to demonstrate a site response directivity, because a concentration of $H / V$ peaks along an azimuth could also result from the presence of sources of polarised noise. Nevertheless, the persistence of similar maxima of DHVPOR values in data acquired at different times (possibly obtained from recordings carried out in different seasons), if combined with the observation that such preferential direction is not present at nearby sites during contemporary recording, provides robust evidence of directional resonance properties specific of the investigated site.

\section{Results}

\subsection{Measurements at accelerometer sites on landslide-prone slopes}

Early recordings of small-moderate-magnitude earthquakes by the Caramanico accelerometer network demonstrated that sites CAR2 and CAR3 (Fig. 1) are characterised by a pronounced site response directivity with maximum of ground motion along azimuths of $80^{\circ}-110^{\circ}$ and $120^{\circ}-130^{\circ}$, respectively (Del Gaudio and Wasowski, 2007). The presence of directional phenomena has been further confirmed following the recordings of a large number of events belonging to the seismic sequence that in 2009 hit L'Aquila (about $60 \mathrm{~km}$ NW of Caramanico), with a mainshock of moment magnitude $M_{\mathrm{w}}=6.3$ (Del Gaudio and Wasowski, 2011). Figure 2 shows the SSR values obtained for CAR2 and CAR3, using CAR4 as a reference station.

For CAR2 (Fig. 2a), the SSR values were derived from 23 seismic events mostly between 40 and $60 \mathrm{~km}$ distant: the highest peak (amplification factor $\mathrm{AF}=10 \pm 3$ ) was observed along an azimuth of $100^{\circ} \pm 33^{\circ}$ at a frequency of $2.3 \pm 0.1 \mathrm{~Hz}$. This appears to be a major resonance frequency, possibly related to the effects of the $40 \mathrm{~m}$-thick colluvium. Seismic investigations conducted at this site using the ReMi technique provided for shear wave velocity Vs an average estimate of about $400 \mathrm{~m} \mathrm{~s}^{-1}$ (Coccia et al., 2010). Following the simplified relation connecting surface layer $V_{\mathrm{S}}$ velocity and thickness $H$ to resonance frequency $F_{o}$ (i.e. $\left.F_{o}=V_{\mathrm{s}} / 4 H\right)$, this velocity value provides an estimate of $F_{o}=2.5 \mathrm{~Hz}$.

Other similarly oriented significant peaks were observed at frequencies of 3.3 and $6.5-7 \mathrm{~Hz}(\mathrm{AF} \approx 8), 1.5$ and $4.7 \mathrm{~Hz}$ $(\mathrm{AF} \approx 7.5), 8.5-9 \mathrm{~Hz}(\mathrm{AF} \approx 6.5), 9-10 \mathrm{~Hz}(\mathrm{AF} \approx 6)$ and $12.5 \mathrm{~Hz}(\mathrm{AF} \approx 4.5)$. All the amplification factors observed at different frequencies along directions of maxima exceed

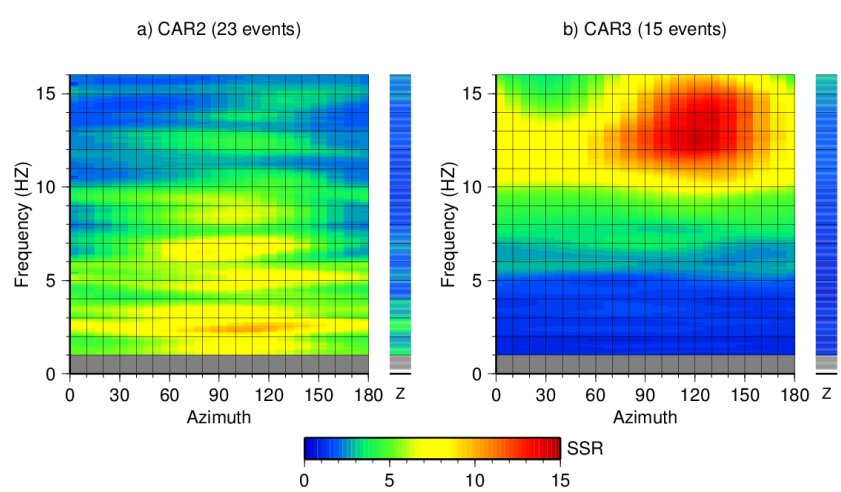

Fig. 2. Azimuthal variation of SSR values obtained for the sites of the accelerometer stations CAR2 (a) and CAR3 (b), averaging spectral ratios calculated for 23 and 15 seismic events, respectively, in comparison to the reference site CAR4. Vertical bars show the SSR values relative to vertical component.

those at the same frequency along orthogonal directions by a factor ranging from 1.5 to 3 . Additional secondary peaks were found along an azimuth of $130^{\circ}$ (e.g. at $5.0-5.5 \mathrm{~Hz}$ ), but with a less pronounced directional character.

Comparatively, the structure of the SSR diagram appears simpler for CAR3 (Fig. 2b) located on fractured rock, which seems to cause strong amplification at relatively higher frequencies. In this case the average of 15 events revealed a band of strong directional maxima extending between 10 and $16 \mathrm{~Hz}$, oriented along an azimuth of $120^{\circ}-130^{\circ}$, with two major peaks at frequencies of 12.6 and $13.6 \mathrm{~Hz}$, both characterised by an $\mathrm{AF}=14 \pm 4$. The amplification along an approximately orthogonal direction was about $50 \%$ lower.

These new SSR results appear consistent with those obtained from the first ambient noise recording campaign carried out in July 2007 using a Tromino tomograph prototype (Del Gaudio et al., 2008). The azimuthal variation of HVNR values in Fig. 3 shows major directional peaks corresponding to the main SSR peaks found at CAR2 and CAR3 (Fig. 3). At CAR2 the maximum $H / V$ was found at a frequency of $2.4 \pm 0.1 \mathrm{~Hz}$ along an azimuth of $80^{\circ} \pm 22^{\circ}$, whereas at CAR3 the peak frequency was $12.7 \pm 0.3 \mathrm{~Hz}$ along an azimuth of $130^{\circ} \pm 20^{\circ}$.

Interestingly, at site CAR3 the peak value of $H / V$ ratios $(12.6 \pm 3.8)$ is in excellent agreement with the mean AF value derived from seismic event analysis, whereas at CAR2 the $H / V$ maximum of $4.2 \pm 1.6$ is much smaller than the corresponding mean AF. This difference appears related to the presence of amplification affecting vertical components: recordings of earthquakes showed that at frequencies where horizontal ground motion amplification is maximum, site CAR2 is also affected by a concomitant amplification of the vertical component by a factor of about 4 (see Fig. 2), whereas at CAR3 vertical amplification factor is absent or negligible (less than 2). A secondary maximum observed at 

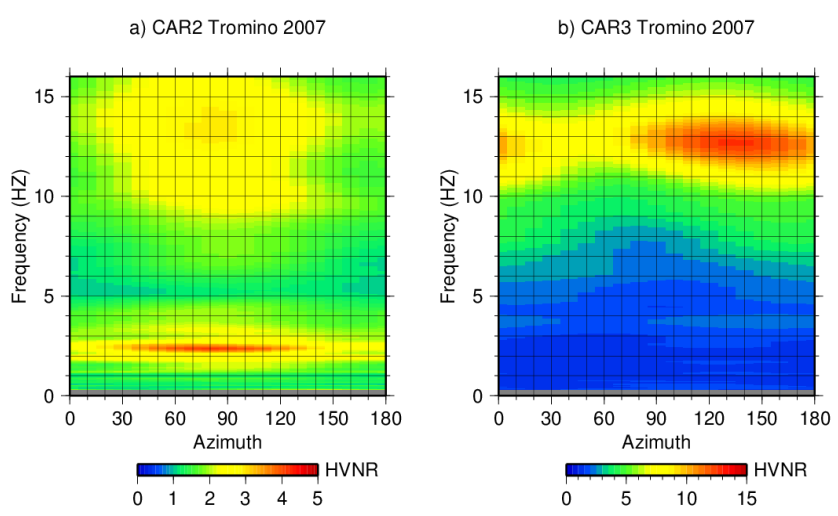

Fig. 3. Azimuthal variation of HVNR values at the sites CAR2 (a) and CAR3 (b) from noise measurements carried out on July 2007 using a tomograph.

CAR2 at a frequency of $13.2 \pm 0.7 \mathrm{~Hz}$ shows an $H / V$ amplitude (3.0 \pm 0.6$)$ comparable to the $\mathrm{AF}(4.6 \pm 2.1)$ derived from SSR values at $12.5 \mathrm{~Hz}$, a frequency where vertical component amplification is absent.

The relation between vertical amplification and $H / V$ ratio values deserves a supplementary discussion. Albarello and Lunedei (2009), investigating the simple case of flat horizontal layering with a low impedance layer overlying a stiffer substratum, found that peak amplitude of noise $H / V$ ratios in different situations may reflect $S$ waves amplification or Rayleigh wave ellipticity (i.e. the ratio between horizontal and vertical component of the elliptical Rayleigh particle motion): $S$ waves amplification appears to have a major influence on $H / V$ ratios around the site fundamental resonance frequency and for closer noise sources, whereas for higher frequencies and more distant sources the effect of Rayleigh wave ellipticity seems to prevail, causing an increase of $H / V$ ratios beyond the amplification factor observed during earthquakes.

Whatever the proportion between body and surface waves may be in the noise, one can expect that $H / V$ ratios can be reduced by the presence of a shallow layer characterised by low $P$ wave velocity $\left(V_{\mathrm{p}}\right)$. Indeed, considering that on soft soil body wave contribution to noise vertical ground motion is dominated by $P$ waves, a strong contrast of $V_{\mathrm{p}}$ values between shallow layer and substratum would imply a decrease of $H / V$ ratios as effect of vertical motion amplification; on the other hand, low $V_{\mathrm{p}}$ values at surface generally implies a low Poisson's ratio as well, which can cause a considerable decrease of Rayleigh wave ellipticity (Tuan et al., 2011).

Significantly, $V_{\mathrm{p}}$ values in shallow unconsolidated porous layers (e.g. colluviums) are strongly influenced by water content, whose increase determines an increase both of $V_{\mathrm{p}}$ and of Poisson's ratio. This suggests a possible explanation of the variable results obtained from noise measurements in June 2010 at CAR2 and CAR3, using the broad-band sensor, and in May 2011 at CAR2, using simultaneously the tomograph and the broad-band sensor. Whereas, with respect to the first results from July 2007, the new measurements at CAR3, sited on cemented carbonate breccias, substantially confirmed the earlier findings with regard to frequency $(13.1 \pm 0.4 \mathrm{~Hz})$ and orientation $\left(130^{\circ} \pm 18^{\circ}\right)$ of the major peak, with only a limited decrease of the $H / V$ peak value $(9.1 \pm 1.6$ ), the new HVNR measurements at CAR2 (sited on thick colluvial deposits) showed a considerable weakening of the peak around $2.5 \mathrm{~Hz}$ (with $H / V$ dropped to 2.2-2.5). This can perhaps be related to seasonal variations of water table at CAR2, which in the month of July is expected to be close to the maximum following late-fall/winter/early-spring groundwater recharge.

This raises the problem of the stability of noise recording results in terms of resonance properties identification in cases when analysis relies on azimuth/frequency distribution of mean $H / V$ ratio values alone. Therefore, the use of the DHVPOR approach is advocated here to support the analysis of directional resonance: the persistent recurrence of $H / V$ relative maxima for a given azimuth/frequency combination, during recordings carried out at different times, can lead to identifying main resonance frequencies even in the presence of a strong variability of $H / V$ ratios.

Figure 4 shows the histograms of the DHVPOR values obtained for the four noise measurements carried out at CAR2 located on the 1989 landslide. The noise recordings reveal the presence of significant directional peaks concentrated within a azimuth interval between $80^{\circ}$ and $110^{\circ}$; such peaks are almost absent along other directions at least for frequencies higher than $3 \mathrm{~Hz}$. Below this frequency directional $H / V$ peaks appear oriented also along different azimuths, even though, at least above $1 \mathrm{~Hz}$, the relative maxima of their occurrence rate are constantly within the $80^{\circ}-$ $110^{\circ}$ azimuth range. The more dispersed orientation of $H / V$ peaks at lower frequencies can reflect the fact that, due to the weaker attenuation of such frequencies, contributions to local noise wavefield arrive from more distant sources characterised by different polarisations.

Comparatively, no systematic preferential direction was observed in $H / V$ peaks recorded at sites CAR1 and CAR5 (Fig. 5), located on the same slope but outside the 1989 landslide. This is consistent with the results of earthquake recording analyses, which demonstrated that these sites are not affected by response directivity (Del Gaudio and Wasowski, 2011).

A general consideration based on the examination of the DHVPOR histograms (Figs. 4 and 5) is that the maximum occurrence rates of directional peaks are not particularly high (less than $50 \%$ of time windows showed significant directional peaks in all the examined cases). This implies that, for most of a noise recording session, signals do not show a pronounced polarisation. Nonetheless, when polarised signals appear at sites characterised by response directivity, they tend to have common orientation consistent with that of the site directional resonance. This suggests that the majority of 

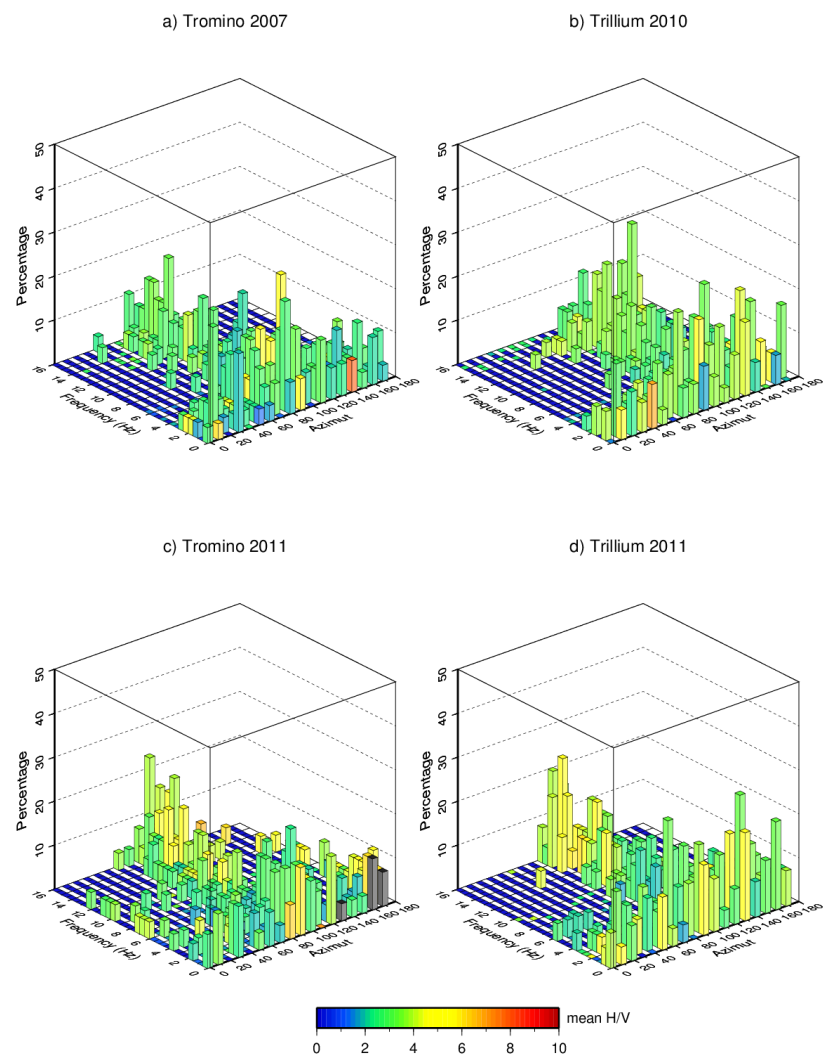

Fig. 4. Histograms of DHVPOR (directional $H / V$ peak occurrence rate) values obtained for noise measurements carried out at site CAR2 in 2007 with the tomograph (a), in 2010 with the broadband sensor (b) and in 2011 using simultaneously the tomograph (c) and the broad-band sensor (d). The colours represent, according to the reported scale, the average of $H / V$ peak values in recording time windows along different azimuths and within $0.5 \mathrm{~Hz}$ frequency intervals.

the recorded signal consists of weak background noise that does not reflect the site resonance properties. Therefore, to investigate the possibility of deriving more details on resonance frequencies from noise analysis, it is of interest to examine the results obtained restricting the average of $H / V$ ratios only to those corresponding to relative maxima.

In general, the $H / V$ peak values belonging to each azimuth/frequency bin showed a moderate dispersion around their average (standard deviation typically about $1 / 3$ of the average), except for frequencies below $1 \mathrm{~Hz}$, often characterised by standard deviation close to or even larger than the average. Thus at microseismic frequencies the signal seems affected by a strong variability related to noise source properties, which hampers the recognition of site-specific features of spectral ratios. Figure 6 shows, as function of frequency, the average values of $H / V$ relative maxima found for frequency intervals of $0.5 \mathrm{~Hz}$ along directions of maximum concentration of peak occurrence. For CAR3 this diagram reveals consistent results for the two measurements
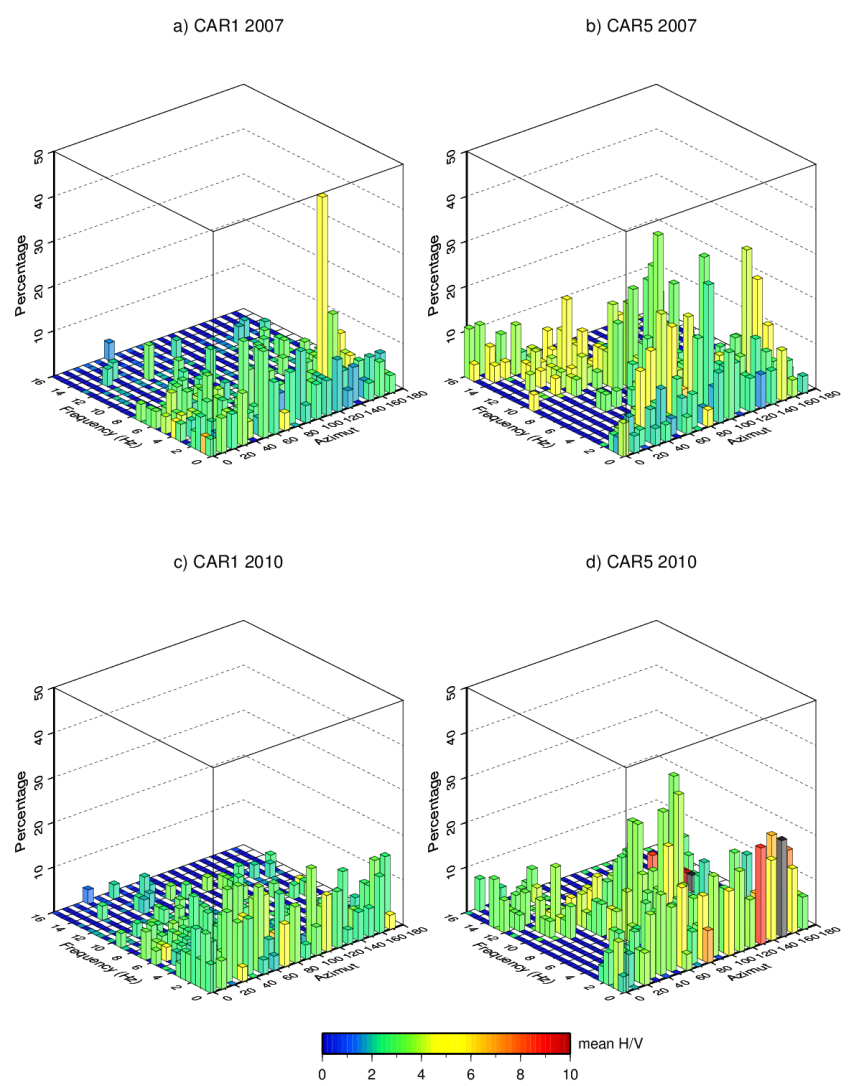

Fig. 5. Histograms of DHVPOR values obtained for noise measurements carried out using tomographs in 2007 (a and b) and in 2010 (c and d) at sites CAR1 and CAR5, respectively.

of 2007 and 2010, with a major peak corresponding to frequency and orientation of the directional resonance revealed by the earthquake recordings. For CAR2, the general pattern of mean $H / V$ peak ratios observed at different times along an azimuth $\left(90^{\circ} \mathrm{N}\right)$ characterised by high recurrence of significant $H / V$ peaks appears consistent, with a first major peak around $2 \mathrm{~Hz}$ frequency and a series of other peaks between 4 and $13 \mathrm{~Hz}$, with the largest one around $12.5 \mathrm{~Hz}$. This pattern is comparable to that of the SSR values calculated along the same azimuth, even though up to about $10 \mathrm{~Hz}$ the $H / V$ spectral ratios are largely below the SSR. Thus, through this kind of analysis it is possible to obtain (at least) a rough indication of main resonance frequencies, even in the case of complex site-spectral response.

\subsubsection{Measurements at other landslide-prone sites}

Measurements carried out at site T7 (Fig. 1) on the Ischio landslide did not show evidence of a significant site response. HVNR values (Fig. 7a) have only one peak satisfying the significance requirements described in Sect. 3., i.e. a weak maximum of $2.3 \pm 0.7$ at a frequency of $1.4 \pm 0.1 \mathrm{~Hz}$ due $40^{\circ} \mathrm{N} \pm 23^{\circ}$. The DHVPOR histogram (Fig. 7b) shows that 
a) CAR2

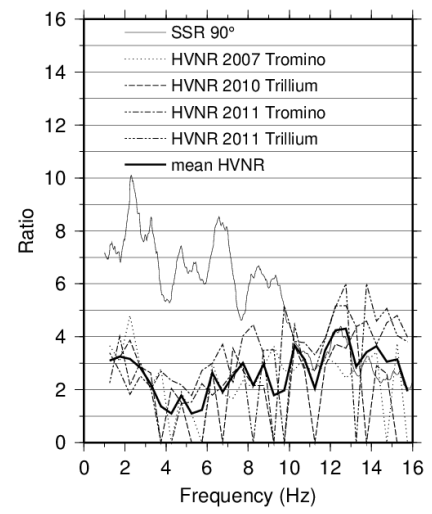

b) $\mathrm{CAR} 3$

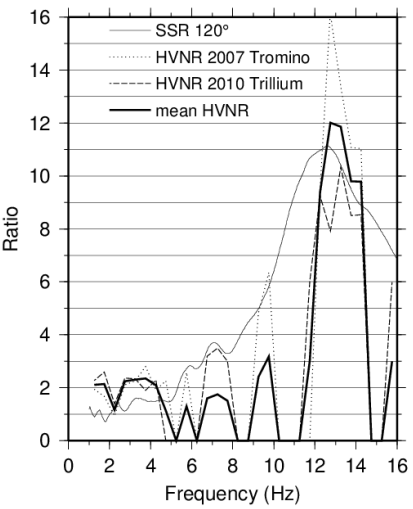

Fig. 6. Diagram of spectral ratios along a direction characterised by a high recurrence of significant directional maximum at site CAR2 (a) and CAR3 (b). Thin solid line represents the SSR values obtained along the azimuths specified in legend; other lines represent mean values of noise $H / V$ peaks having the same directions and frequencies binned by $0.5 \mathrm{~Hz}$ intervals, resulting from different HVNR measurements (see legend); thick solid line represents the average of noise $H / V$ peak values derived from the HVNR measurements.
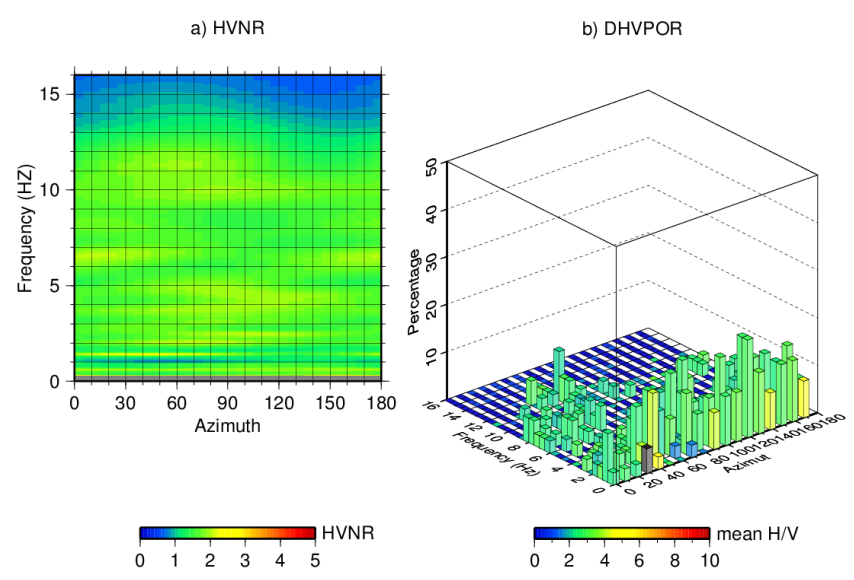

Fig. 7. Results of noise measurements at site T7 (Ischio landslide): (a) mean HVNR diagram; (b) DHVPOR histogram.

directional $H / V$ maxima in recording time windows are mostly found at low frequencies with a wide variability of directions and relatively low values of spectral ratios. The absence of clear site effects could be related to the limited thickness $(<5 \mathrm{~m})$ of the "slow" carbonate debris material and the lack of impedance contrast.

Measurements in the 1627 landslide area were carried out with tromographs at three sites, distant about one hundred metres from each other: one (T6) is located in the central part of the accumulation zone of the landslide, and the others (T6S and T6N) are close to its boundary. A first recording session was conducted in May 2011 at the site T6. In

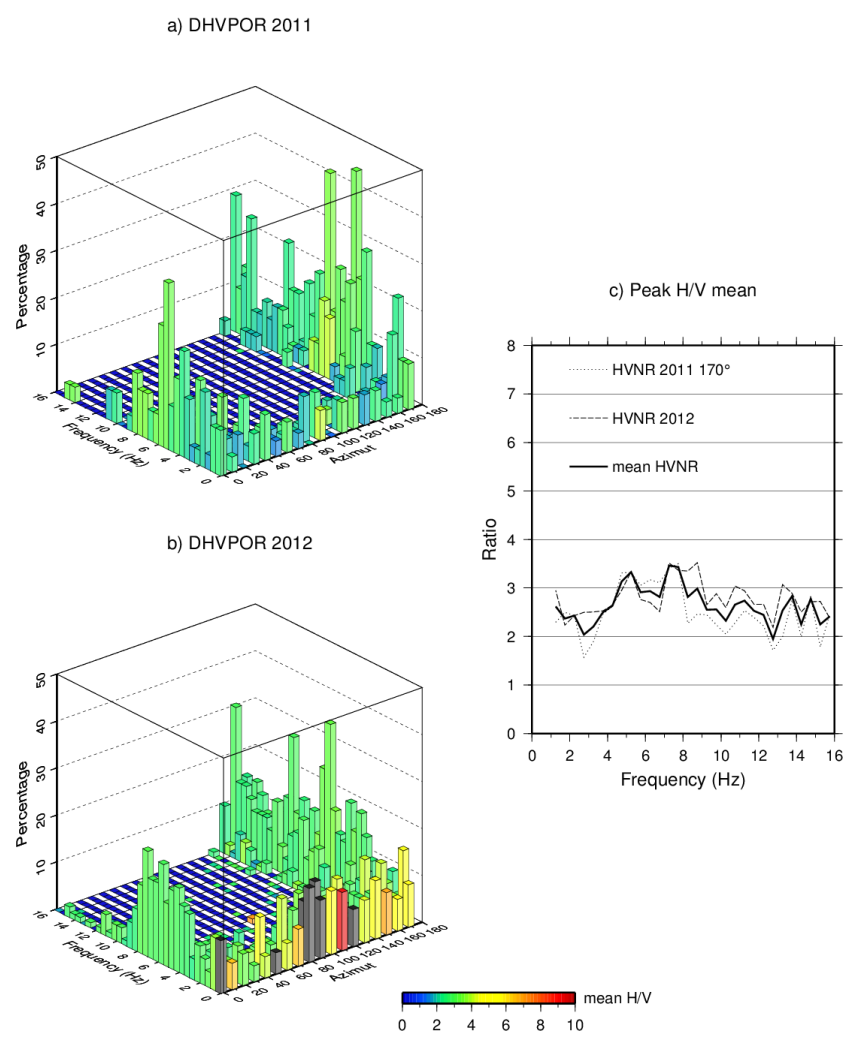

Fig. 8. Results of noise measurement at site T6 (1627 landslide): DHVPOR histograms relative to measurements of May 2011 (a) and January 2012 (b) and mean values of $H / V$ peaks oriented due $170^{\circ} \mathrm{N}$; thick solid line represents the average of noise $H / V$ peak values derived from different measurements.

January and May 2012 measurements were repeated at T6 and additional sites were investigated. In January 2012 two instruments were used simultaneously, one kept fixed at T6S and the other employed as a "rover" for measurements at T6 and $\mathrm{T} 6 \mathrm{~N}$.

DHVPOR histograms show that T6 seems affected by a response directivity approximately $\mathrm{N}-\mathrm{S}$ oriented, with azimuth range of $170^{\circ}-180^{\circ}$ (Fig. 8). This directivity cannot be attributed to noise source properties (e.g. dominant winds shaking trees), because the measurements carried out simultaneously at T6S revealed a weak directivity oriented E-W. Measurement carried out at different times show that the average of $H / V$ peak values along the azimuth of $170^{\circ}$ appear consistent and indicate two maxima at frequencies of about 5 and $7.5 \mathrm{~Hz}$ (Fig. 8c).

Conversely, no significant site effect was detected at T6S (Fig. 9): indeed, despite the presence of a common preferential orientation of rare polarised signals, the $H / V$ ratios fall very close to the threshold of 2 (Fig. 9d). The low $H / V$ ratios could perhaps be related to the location of this site at the margin of the main landslide body, where thickness of the disturbed material is greatly reduced. Some weak evidence 

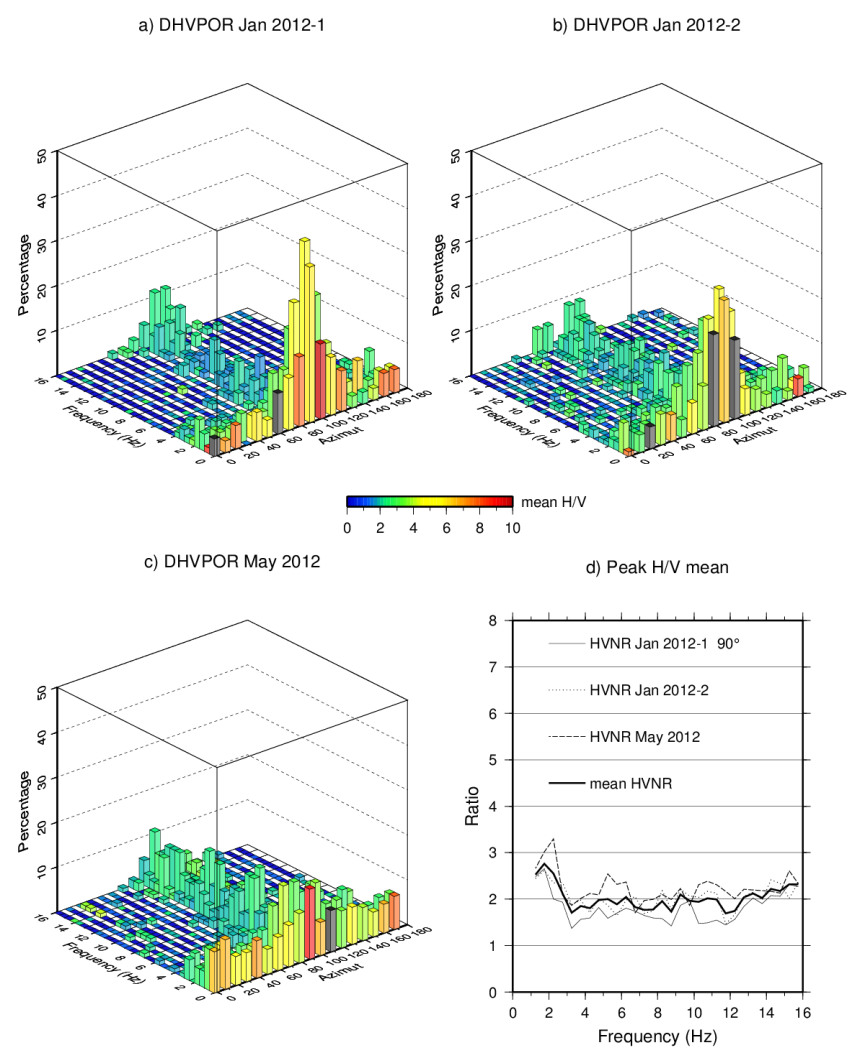

Fig. 9. Results of noise measurement at site T6S (1627 landslide): DHVPOR histograms relative to measurements of January $(\mathbf{a}, \mathbf{b})$ and May 2012 (c) and mean values of $H / V$ peaks oriented due $90^{\circ} \mathrm{N}$; thick solid line represents the average of noise $H / V$ peak values derived from different measurements. Note that the first of the two January measurements was simultaneous with that at site T6 (Fig. 8b), whereas the second one was simultaneous with that at site T6N (Fig. 10a)

of directivity was found at site T6N (Fig. 10) with azimuth $120^{\circ}-130^{\circ}$. The analysis of the mean $H / V$ peak values along this direction (Fig. 10c) provided consistent results in two different data acquisitions, showing a maximum of spectral response at frequencies between 8 and $13 \mathrm{~Hz}$, even though with modest (around 3) $H / V$ ratios.

At present it is unclear what factors may determine the directivity at $\mathrm{T} 6$ and, to a minor extent, at $\mathrm{T} 6 \mathrm{~N}$. The exact location of the 1627 landslide detachment zone and the main sliding direction are somewhat uncertain (Wasowski et al., 2013). Nevertheless, considering the WSW-facing slope geometry, it seems likely that slide movement direction is close to being orthogonal to the response directivity at $\mathrm{T} 6$ as indicated by noise analysis. Thus, this case is different from the landslide at CAR2, where directivity is present along the maximum slope direction.

Finally, noise measurements were conducted also in an area that is a major source of rockfalls at Caramanico, i.e. at the caprock of the Colle Alto hill. Measurements were

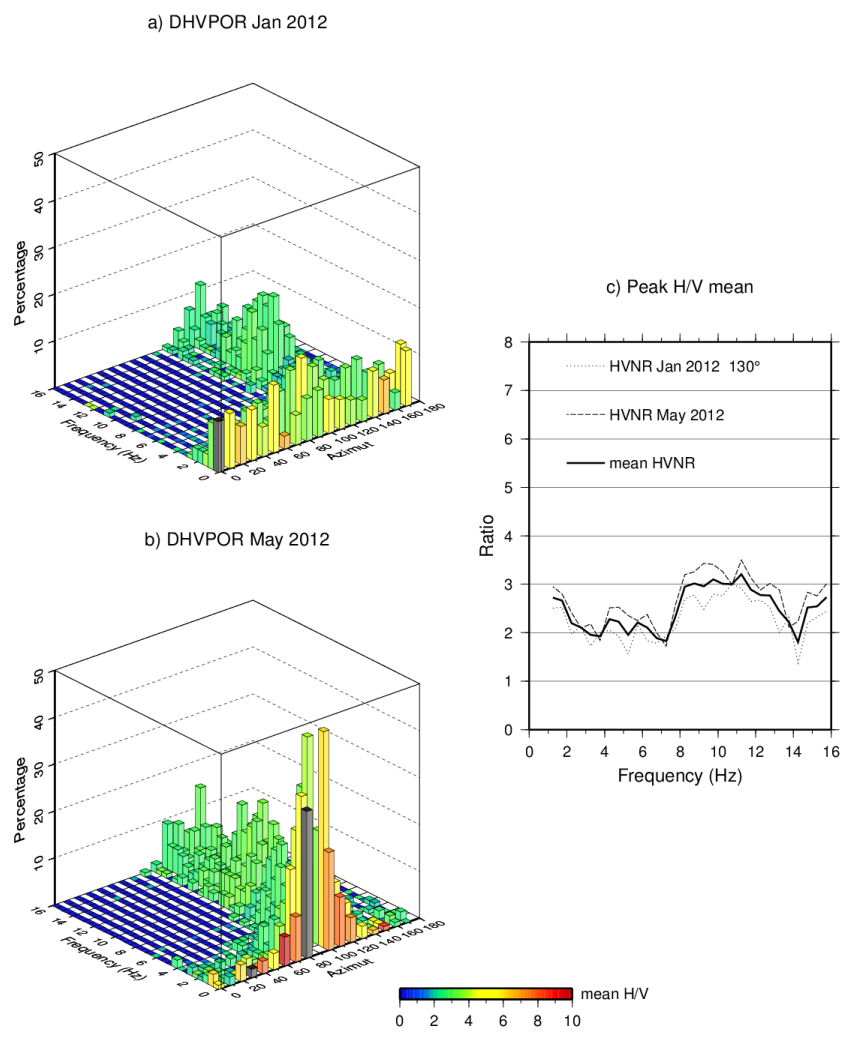

Fig. 10. Results of noise measurement at site T6N (1627 landslide): DHVPOR histograms relative to measurements of January (a) and May (b) 2012 and mean values of $H / V$ peaks oriented due $130^{\circ} \mathrm{N}$; thick solid line represents the average of noise $H / V$ peak values derived from different measurements.

carried out in December 2011 and May 2012 on two sites, one (T4) on the rim of the caprock with west-facing steep scarp, and the other (T4E) a few tens of metres to the east of T4 (Fig. 1).

Measurements of December 2011 suggested a possible $\mathrm{E}-\mathrm{W}$ directivity at $\mathrm{T} 4$ and, less pronounced, also at T4E (Fig. 11a-b), but in the data acquired in May 2012 evidence of such directivity appeared much weaker at $\mathrm{T} 4$ and practically absent at T4E (Fig. 11c-d). However, mean values of $H / V$ peaks oriented along the $\mathrm{E}-\mathrm{W}$ direction seem to indicate that a significant resonance may be present at $\mathrm{T} 4$ (Fig. 12a), possibly without a pronounced directional character, with maxima of spectral response around 8 and $12 \mathrm{~Hz}$. Moving away from the caprock rim (and the steep scarp), at T4E this resonance appears weaker (Fig. 12b), which suggests a possible relation with local topography.

\section{Discussion and conclusions}

The new results of ambient noise analysis concerning slopes affected by or prone to landslides indicate that they can be characterised by a complex seismic response showing 

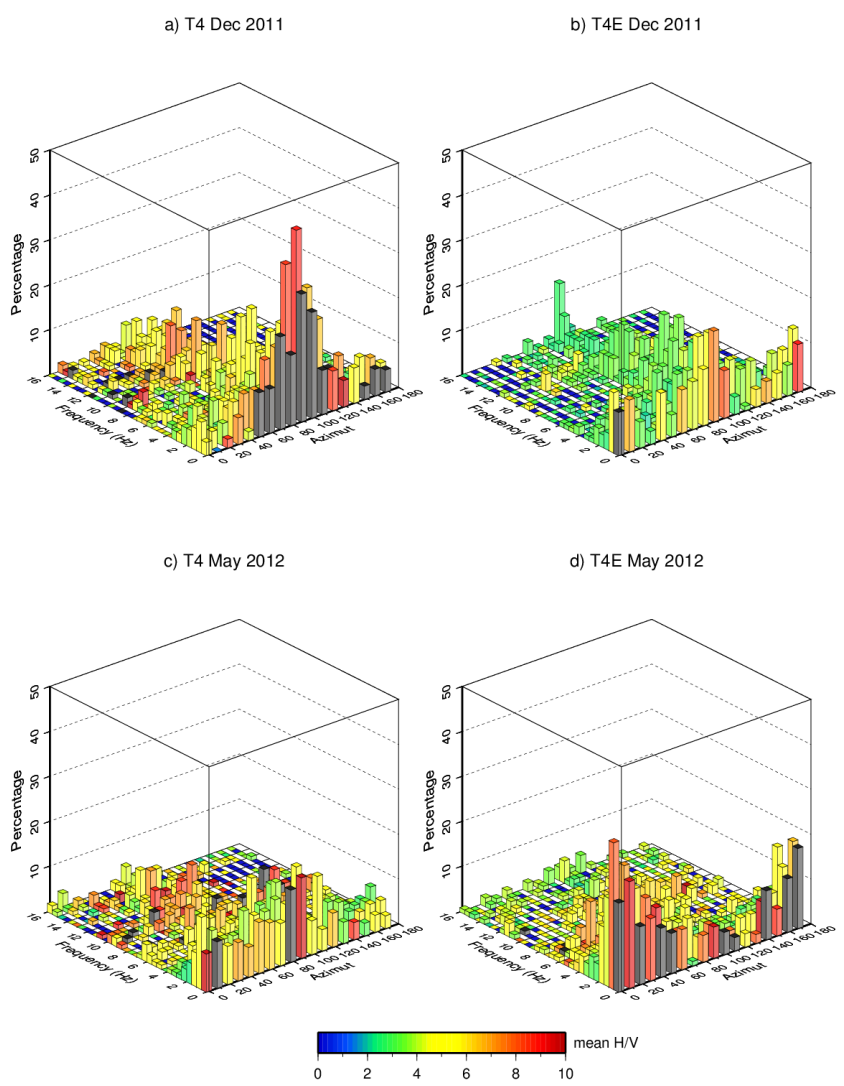

Fig. 11. Histograms of DHVPOR values relative to noise measurements carried out at sites T4 and T4E (Colle Alto hill) in December 2011 and May 2012.

pronounced directional variations. This complexity requires a more sophisticated analysis in order to draw reliable information on site resonance properties. Furthermore, to improve our comprehension of relations between seismic noise signal properties and response under seismic shaking, more ambient noise data ought to be collected, especially at sites where results from seismic ground motion monitoring are available. This is related to a general need to acquire more data from accelerometer stations sited on hillslopes (including potentially unstable slopes). Indeed, the available recordings of actual strong motions affecting slopes are very few and generally limited to the aftershock phases (Wasowski et al., 2011). The tests conducted at the sites of the Caramanico accelerometer network suggest that standard techniques of ambient noise analysis may produce unreliable results under conditions characterised by possible variations of body wave amplification and/or Rayleigh wave ellipticity related to changing site conditions (e.g. seasonal hydrogeological variations). These variations can modify the horizontal-tovertical spectral ratios of noise, thereby "hiding" important resonance frequencies.
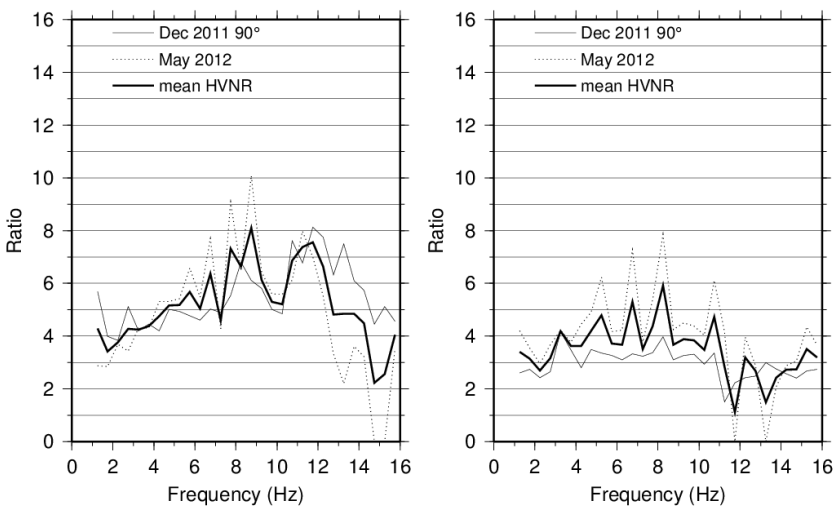

Fig. 12. Mean values of $H / V$ peaks oriented due $90^{\circ} \mathrm{N}$ resulting from noise measurements at sites $\mathrm{T} 4$ (a) and $\mathrm{T} 4 \mathrm{E}$ (b), on the rim of the megabreccia scarp; thick solid line represents the average of noise $H / V$ peak values derived from different measurements.

Given the variability shown by signal properties, adequate criteria need to be defined to select the portions of the recorded signals that best reflect the site resonance properties. In particular, in a scarcely noisy environment (e.g. far from urbanised zones), a "global" $H / V$ average could be biased by spectral ratios belonging to very weak signals having a low signal/noise ratio: such a ratio in this context is to be intended as the ratio between coherent and incoherent part of the noise, where the coherence mainly derives from Rayleigh waves which can provide relevant information on site response characteristics.

Importantly, when polarised noise signals are recorded at sites characterised by seismic response directivity, they show a coherent direction of polarisation that is also consistent with maximum resonance direction. Thus, while investigating directional resonance, it is better to analyse an average restricted to the part of noise signal that shows a clear polarisation with a coherent preferential orientation rather than focusing on a global average of total recorded $H / V$ ratios. A simple way to do it consists of averaging $H / V$ relative maxima observed in different time windows along directions of persistent recurrence of significant peaks.

The extension of noise analysis below $1 \mathrm{~Hz}$ still appears difficult for the strong variability of signal polarisation observed at such frequencies. It is unclear whether this is due to a lack of directivity for the investigated sites at these frequencies or to the superimposition of too many signals arriving from more distant sources of differently polarised noise, as an effect of the weaker attenuation of low frequencies. Perhaps in this case it will be necessary to adopt a more refined method of selection of useful signal portion, analysing comparatively recordings acquired simultaneously at more sites to filter strongly polarised signals coming from distant sources. 
Another open question concerns the identification of factors controlling site response directivity. Our experience shows that, even though this phenomenon is recurrent in landslide areas, no systematic relation was observed in terms of site characteristics or between resonance and slope directions. Among the landslide cases examined here, one (CAR2) shows a directivity parallel to the sliding direction, whereas for the other (T6) the relation with the directions of prominent topographic features remains unclear. Similar tests were also recently conducted in Taiwan on slopes affected by large landslides triggered by the $1999 M=7.6$ Chi-Chi earthquake. In one case (Jufengershan landslide) HVNR values showed evidence of directivity parallel to the slide direction, which also coincides with dip direction of a monoclinal bedding. In the second case (Tsaoling landslide) the sliding direction does not coincide with HVNR maximum direction, even though HVNR values were very high (about 15) along the maximum slope direction as well.

The possible presence of a directional resonance parallel to potential sliding directions is a factor that should be taken into account in evaluating slope susceptibility to seismic failures. For instance, this can be done in a regionalscale hazard assessment, following the empirical approach proposed by Jibson (2007) to evaluate Newmark's permanent displacement. Accordingly, one can estimate that an increase of ground motion by $50 \%$ along potential sliding direction implies a median increase of Newmark's displacement by a factor of 5 , thus noticeably modifying the outcome of hazard assessment.

On the whole, the analysis of ambient noise seems very useful because, through low-cost investigations, it can lead to the detection of directional resonance phenomena and to the recognition of their orientations. Although a simple examination of azimuthal variation of mean $H / V$ spectral ratios in a single station may not be sufficient to identify directional resonance properties of a site, a comparison between simultaneous recordings at nearby sites under different geological conditions can resolve the question of whether directivity revealed by HVNR measurements is site specific or is due to the noise source. Furthermore, for a correct identification of main resonance frequencies, more advanced signal analysis is needed including a proper selection of portions of noise recordings that are most representative of site response properties. In this context it is useful to compare recordings obtained at different times and under different seasonal conditions to recognise persistent site-specific properties of ground vibration.

Finally, considering efforts aimed at an approximate quantification of spectral amplification factors, it seems that their success can in some cases depend on specific site conditions. In particular, where the vertical component of ground motion is not amplified, the $H / V$ peak values appear to approximate well mean amplification factors. The presence of a strong variability of $H / V$ peak values among measurements carried out at different times could result from changing site conditions. In such a case numerical modelling of slopes could perhaps help to provide constraints on amplification estimates, but this implies the acquisition of detailed (and typically costly) data on geometrical-physical characteristic of slope materials.

Acknowledgements. We thank Alessandro Pasuto (CNR-IRPI, Padova) for lending us one Tromino tromograph for the noise recordings of May 2011 and anonymous reviewers for helpful comments. We also acknowledge long-term support by the Municipality of Caramanico and in particular Mayor Mario Mazzocca.

Edited by: F. Guzzetti

Reviewed by: two anonymous referees

\section{References}

Albarello, D. and Lunedei, E.: Alternative interpretations of horizontal to vertical spectral ratios of ambient vibrations: new insights from theoretical modeling, Bull. Earthquake Eng., 8, 519534, doi:10.1007/s10518-009-9110-0, 2009.

Asten, M. W.: Comment on "Microtremor observations of deep sediment resonance in metropolitan Memphis, Tennesse", by Paul Bodin, Kevin Smith, Steve Horton and Howard Hwang, Eng. Geol., 72, 343-349, 2004.

Bard, P. Y. (coordinator) and The SESAME Team: Guidelines for the implementation of the $H / V$ spectral ratio technique on ambient vibrations: measurements, processing and interpretation. SESAME European research project, WP12 - Deliverable D23.12, available at: ftp://ftp.geo.uib.no/pub/seismo/SOFTWARE/SESAME/ USER-GUIDELINES/SESAME-HV-User-Guidelines.pdf (last access: August 2013), 2004.

Bonnefoy-Claudet, S., Cotton, F., and Bard, P.-Y.: The nature of seismic noise wavefield and its implications for site effects studies - A literature review, Earth Sci. Rev., 79, 205-227, 2006.

Borcherdt, R. D.: Effects of local geology on ground motion near San Francisco Bay, Bull. Seism. Soc. Amer., 60, 29-61, 1970.

Bourdeau, C. and Havenith, H.-B.: Site effects modeling applied to the slope affected by the Suusamyr earthquake (Kyrgyzstan, 1992), Eng. Geol., 97, 126-145, 2008

Bozzano, F., Lenti, L., Martino, M., Paciello, A., and Scarascia Mugnozza, G.: Self-excitation process due to local seismic amplification responsible for the reactivation of the Salcito landslide (Italy) on 31 October 2002, J. Geophys. Res., 113, B10312, doi:10.1029/2007JB005309, 2008.

Bromirski, P. D., Duennebier, F. K., and Stephen, R. A.: Midocean microseisms, Geochem. Geophys. Geosy., 6, Q04009, doi:10.1029/2004GC000768, 2005.

Castellaro, S. and Mulargia, F.: $V_{30}$ Estimates Using Constrained $H / V$ Measurements, Bull. Seismol. Soc. Am., 99, 761-773, 2009.

Coccia, S., Del Gaudio, V., Venisti, N., and Wasowski, J.: Application of Refraction Microtremor (ReMi) technique for determination of 1-D shear wave velocity in a landslide area, J. Appl. Geophys., 71, 71-89, doi:10.1016/j.jappgeo.2010.05.001, 2010. 
Del Gaudio, V. and Wasowski, J.: Directivity of slope dynamic response to seismic shaking, Geophys. Res. Lett., 34, L12301, doi:10.1029/2007GL029842, 2007.

Del Gaudio, V. and Wasowski, J.: Advances and problems in understanding the seismic response of potentially unstable slopes, Eng. Geol., 122, 73-83, 2011.

Del Gaudio, V., Coccia, S., Wasowski, J., Gallipoli, M. R., and Mucciarelli, M.: Detection of directivity in seismic site response from microtremor spectral analysis, Nat. Hazards Earth Syst. Sci., 8, 751-762, doi:10.5194/nhess-8-751-2008, 2008.

Del Gaudio, V., Lee, C. T., and Wasowski, J.: Inferring seismic response of landslide-prone slopes from microtremor study, Proc. Second World Landslide Forum, Rome, 3-7 October, 2011.

Gallipoli, M. R. and Mucciarelli, M.: Effetti direzionali in registrazioni sismometriche in aree in frana e bordi di bacino, XXVI GNGTS Conference, Rome, 13-15 November 2007, available at: http://www2.ogs.trieste.it/gngts/gngts/convegniprecedenti/ 2007/presentazioni/2_22/2_22_14_Gallipoli_frane.pdf, 2007.

Garambois, S., Quintero, A., Massey, C., and Voisin, C.: Azimuthal and thickness variabilities of seismic site effect response of the Utiku landslide (North Island, New-Zealand), Geophys. Res. Abstr., vol. 12, EGU2010-2430, EGU General Assembly 2010, Vienna, 2-7 May 2010, 2010

Harp, E. L. and Jibson, R. W.: Anomalous concentrations of seismically triggered rock falls in Paicoma Canyon: are they caused by highly susceptible slopes or local amplification of seismic shaking?, Bull. Seismol. Soc. Am., 92, 3180-3189, 2002.

Harp, E. L., Wilson, R. C., and Wieczorek, G. F.: Landslides from the February 4, 1976, Guatemala earthquake, USGS Professional Paper 1204-A, 40 pp., 1981.

Haubrich, R. A., Munk, W. H., and Snodgrass, F. E.: Comparative spectra of microseism and swell, Bull. Seismol. Soc. Am., 53, 27-37, 1963.

Jibson, R. W.: Regression models for estimating coseismic landslide displacement, Eng. Geol., 91, 209-218, 2007.

Lermo, J. and Chávez-García, F. J.: Are microtremors useful in site response evaluation?, Bull. Seismol. Soc. Am., 84, 1350-1364, 1994.

Meunier, P., Hovius, N., and Haines, J. A.: Topographic site effects and the location of earthquake induced landslides, Earth Planet. Sci. Lett., 275, 221-232, 2008.

Moore, J. R., Gischig, V., Burjanek, J., Loew, S., and Fäh, D.: Site Effects in Unstable Rock Slopes: Dynamic Behavior of the Randa Instability (Switzerland), Bull. Seismol. Soc. Am., 101, 3110-3116, 2011.
Nakamura, Y.: A method for dynamic characteristics estimation of subsurface using microtremors on the ground surface, Quarterly Report Railway Tech. Res. Inst., 30, 25-30, 1989.

Nogoshi, M. and Igarashi, T.: On the amplitude characteristics of microtremor (part 2), J. Seismol. Soc. Japan, 24, 26-40, 1971 (in Japanese with English abstract).

Peterson, J: Observation and modeling of background seismic noise, US Geol. Surv. Open-File Rept. 93-322, Albuquerque, 1993.

Schimmel, M., Stutzmann, E., Ardhuin, F., and Gallart, J.: Polarized Earth's ambient microseismic noise, Geochem. Geophys. Geosy., 12, Q07014, doi:10.1029/2011GC003661, 2011.

Sepúlveda, S. A., Murphy, W., Jibson, R. W., and Petley. D. N.: Seismically induced rock slope failures resulting from topographic amplification of strong ground motions: The case of $\mathrm{Pa}-$ coima Canyon California. Eng. Geol., 80, 336-348, 2005.

Tanimoto, T.: Excitation of microseisms, Geophys. Res. Lett., 34, L05308, doi:10.1029/2006GL029046, 2007.

Tuan, T. T., Scherbaum, F., and Malischewsky, P. G.: On the relationship of peaks and troughs of the ellipticity $(H / V)$ of Rayleigh waves and the transmission response of single layer over halfspace models, Geophys. J. Int., 184, 793-800, 2011.

Wasowski, J.: Reactivation of a deep slope movement due to the interruption of spring water withdrawal: case history of the Case Mancini landslide, Italy, Proceedings of the 2nd Panamerican Symposium on Landslides, Novembre 1997, Rio de Janeiro, Brasile, 1, 145-154, 1997.

Wasowski, J.: Understanding landslide-rainfall relationships in man-modified environments: a case history from Caramanico Terme (Italy), Environ. Geol., 35, 197-209, 1998.

Wasowski, J. and Del Gaudio, V.: Evaluating seismically-induced mass movement hazard in Caramanico Terme (Italy), Eng. Geol., 58, 291-311, 2000.

Wasowski, J., Lee, C., and Keefer, D.: Toward the next generation of research on earthquake induced landslides: Current issues and future challenges, Eng. Geol., 122, 1-8, doi:10.1016/j.enggeo.2011.06.001, 2011.

Wasowski, J., Del Gaudio, V., Casarano, D., Lollino, P., and Muscillo, S.: Local scale seismic landslide susceptibility assessment based on historic earthquake records combined with accelerometer monitoring and ambient noise data, in: Earthquake-Induced Landslides, edited by: Ugai, K., Yagi, H., and Wakai, A., Proceedings of the International Symposium on Earthquake-Induced Landslides, Kiryu (Japan), 7-9 November, 2012, Springer, 1120, doi:10.1007/978-3-642-32238-9_2, 2013. 